\title{
Pengaruh Jumlah Iterasi dan Nilai Parameter Relaksasi Terhadap Signal to Noise Ratio (SNR) pada Rekonstruksi Citra Metode SIRT
}

\section{Choirul Anam dan Catur Edi Widodo}

Jurusan Fisika, FMIPA, Universitas Dionegoro, Semarang

Jl. Prof. Dr. Soedarto SH, Tembalang, Semarang, Jawa Tengah

anamfisika@gmail.com

\begin{abstract}
Abstrak - Kualitas citra hasil rekonstruksi metode Simultaneous Iterative Reconstruction Technique (SIRT) ditentukan oleh jumlah iterasi dan nilai parameter relaksasi ( $\lambda$ ). Nilai $\lambda$ ini biasanya diperoleh secara coba-coba. Penelitian ini bertujuan mengevaluasi pengaruh jumlah iterasi dan nilai $\lambda$ terhadap nilai signal to noise ratio (SNR). Rekonstruksi menggunakan obyek fantom Shepp-Logan ukuran 50x50. Proyeksi dilakukan untuk setiap sudut $10^{0}$ menggunakan mode berkas paralel. Pertama ditentukan pengaruh jumlah iterasi terhadap SNR. Selanjutnya dilakukan penentuan nilai SNR untuk variasi $\lambda$ pada jumlah iterasi tertentu. Diperoleh bahwa semakin banyak iterasi dan semakin besar nilai parameter relaksasi menghasilkan nilai SNR semakin tinggi, namun setelah iterasi dan nilai $\lambda$ tertentu, nilai SNR mengalami saturasi. Citra dengan kualitas optimal (kekaburan dan stripping paling kecil), diperoleh pada iterasi antara 5 hingga 10 dan nilai parameter relaksasi antara 0,5 hingga 1 .
\end{abstract}

Kata kunci: SIRT, rekonstruksi citra, parameter relaksasi, SNR

\begin{abstract}
The image quality from Simultaneous Iterative Reconstruction Technique (SIRT) is depend on number of iterations and relaxation parameter's value ( $\lambda$ ). Customaraly, the value of $\lambda$ is determined by trial and error. This research aimed to evaluate the influence of number of iteration and value of $\lambda$ to signal to noise ratio (SNR). The reconstruction using SheppLogan Phantom of size 50x50. The reconstruction was done by angular step of $10^{\circ}$ and using paralel beam mode. Firstly, to determine the influence of number of iteration to SNR. Then, to determine SNR at the variation of $\lambda$ in the certain number of iterations. It was found that the increase of number of iterations and values of $\lambda$, the value of SNR increases. But after reach the certain number of iteration and certain value of $\lambda$, the SNR is saturated. The optimum of image quality (less blurring and stripping) was found at the number of iterations between 5-10 and the values of iterations between 0,5-1.
\end{abstract}

Key words: SIRT, Image reconstruction, relaxation parameter, SNR

\section{PENDAHULUAN}

Dalam rekonstruksi citra tomografi terdapat dua metode utama yang sering digunakan, yaitu metode Fourier (proyeksi balik terfilter, FBP) dan metode aljabar [1,2]. Metode Fourier biasa digunakan untuk data proyeksi yang banyak [3,4], misalnya pada CT Scan. Sedangkan metode aljabar biasa digunakan dalam aplikasi-aplikasi untuk data proyeksi yang sedikit, misalnya pada SPECT.

Kelemahan utama dalam metode aljabar adalah waktu komputasi yang relatif lama [1]. Salah satu teknik untuk meningkat efisiensi komputasi dalam metode aljabar yaitu dengan mempercepat konvergensi pada kompnen frekuensi tinggi $[5,6,7]$.

Selain itu, metode iterasi juga menghasilkan noise yang relatif besar [5]. Untuk mengurangi noise dan mempercepat proses, biasanya digunakan faktor relaksasi $(\lambda)$ dalam persamaan SIRT. Namun penentuan nilai faktor relaksasi ini biasa dilakukan secara coba-coba [8]. Jika pemilihan parameter relaksasi tidak tepat akan menyebabkan terminasi iterasi lebih awal dari yang seharusnya dan menghasilkan perhitungan yang tidak akurat. Biasaya, jika nilai parameter relaksasi terlalu kecil, akan menghasilkan ketidak-akuratan pada detil dengan frekuensi besar. Menurut V. H. Tessa [8]. nilai parameter relaksasi sebaiknya antara $0-1$. Menurutnya parameter relaksasi paling baik dengan nilai 0,1 .

Penelitian ini bertujuan untuk mengevaluasi pengaruh jumlah iterasi dan nilai parameter relaksasi terhadap nilai signal to noise ratio (SNR) serta menentukan optimasi untuk mendapatkan citra paling baik.

\section{LANDASAN TEORI}

Dalam CT atau SPECT, data yang diperoleh adalah data proyeksi. Karena itu tantangannya adalah melakukan rekonstruksi untuk mendapatkan citra tampang lintang suatu obyek [2]. Data proyeksi secara matematis diperoleh dari perkalian matriks pembobot dengan matriks obyek [8].

$$
w^{*} v=p
$$

$v$ merupakan kolom matriks yang menggambarkan nilai dari semua piksel dari citra, $w$ merupakan matriks pembobot yang menggambarkan perjalanan sinar yang melalui piksel tertentu dan $p$ merupakan matriks hasil proyeksi dari suatu citra untuk sudut tertentu. 
Secara matematis persamaan (1) dapat ditulis menjadi sistem persamaan liner:

$$
\begin{gathered}
w_{11} v_{1}+w_{12} v_{2}+w_{13} v_{3}+\ldots+w_{1 N} v_{N}=p_{1} \\
w_{21} v_{1}+w_{22} v_{2}+w_{23} v_{3}+\ldots+w_{2 N} v_{N}=p_{1} \\
w_{31} v_{1}+w_{32} v_{2}+w_{33} v_{3}+\ldots+w_{3 N} v_{N}=p_{1} \\
\vdots \\
w_{M 1} v_{1}+w_{M 2} v_{2}+w_{M 3} v_{3}+\ldots+w_{M N} v_{N}=p_{M}
\end{gathered}
$$

$N$ merupakan jumlah piksel citra. Untuk citra 50x50, nilai $N$ sebesar 2500, sementara $M$ merupakan perkalian banyaknya sudut proyeksi dengan banyaknya piksel salah satu sisi citra. Untuk matriks $50 \times 50$ dan proyeksi setiap $1^{0}$ (dengan total $180^{\circ}$ ), maka besar M adalah 9000. Untuk $N$ dan $M$ yang yang sangat besar, mustahil menyelesaikan persamaan tersebut menggunakan invers matriks. Dalam kondisi ini penggunakan metode iterasi aljabar menjadi pilihan tepat. Metode ini pertama diusulkan oleh Kazmark. Metode ini juga telah sukses diimplementasikan pada CT scan untuk aplikasi medis. Metode iterasi aljabar paling sederhana adalah metode Algebraic Reconstruction Technique (ART). Pada metode ART, dalam setiap sudut dilakukan perubahan nilai piksel suatu citra. Perubahan dilakukan dengan melakukan proyeksi balik, dari hasil selisih proyeksi citra asli dan proyeksi citra hasil rekonstruksi.

Metode ART diimplementasikan dengan persamaan [8]:

$$
v_{j}^{k+1}=v_{j}^{k}+\lambda \frac{p_{i}-\sum_{n=1}^{N} w_{i n} v_{n}^{k}}{\sum_{n=1}^{N} w_{i n}{ }^{2}} w_{i j}
$$

Nilai $v$ awalnya ditentukan dengan nilai tertentu, kemudian diperbaiki oleh suku kedua persamaan (3) untuk setiap sudutnya. Dalam persamaan (3), $\lambda$ menggambarkan parameter relaksasi.

Metode lain yang dibangun menggunakan ART adalah Simultaneous Iterative Reconstruction Technique (SIRT). Dalam algoritma SIRT, perubahan nilai tiap piksel dihitung menggunakan cara yang sama seperti ART, hanya saja perubahan nilai dilakukan dengan memperhatikan seluruh persamaan. Dalam ART perbaikan nilai dilakukan setiap sudut proyeksi, sementara dalam SIRT perubahan nilai dilakukan setelah diperoleh proyeksi untuk satu putaran penuh. Perubahan nilai tiap piksel menggunakan nilai rerata dari semua nilai pada blok tersebut. SIRT dalam beberapa kondisi ekstrim memiliki performa yang lebih baik, misalnya dalam distribusi data yang tidak genap dan data yang tidak komplit.

SIRT diimplementasi dengan persamaan [8]:

$$
v_{j}^{k+1}=v_{j}^{k}+\lambda \frac{\sum_{p_{i} \in P} \frac{p_{i}-\sum_{n=1}^{N} w_{i n} v_{n}^{k}}{\sum_{n=1}^{N} w_{i n}} w_{i j}}{\sum_{p_{i} \in P} w_{i j}}
$$

Dari persamaan 4, pertama dilakukan perkalian tebakan awal untuk nilai piksel dengan matrik pembobot $w$. Dari sini diperoleh data proyeksi untuk data tebakan. Data ini kemudian dikurangkan terhadap data proyeksi asli dari obyek $p$. Lalu hasil selisih kedua data ini dibagi dengan pembobot untuk setiap garis proyeksi, lalu dikalikan lagi dengan matriks pembobot. Semua ini kemudian dibagi lagi dengan penjumlahan dari pembobot untuk semua proyeksi. Data ini kemudian dikalikan dengan parameter relaksasi $\lambda$, yang biasanya nilainya antara 0-1. Data inilah yang digunakan untuk mengubah nilai piksel suatu citra. Hal ini dilakukan terus hingga diperoleh konvergensi.

\section{METODE PENELITIAN}

Rekonstruksi citra tomografi metode SIRT ini menggunakan menggunakan Matlab dengan obyek berupa fantom Shepp-Logan dengan ukuran 50x50. Rekonstruksi metode SIRT ini dilakukan menggunakan persamaan 4. Rekonstruksi menggunakan mode berkas paralel dan proyeksi dilakukan untuk setiap sudut $10^{\circ}$.

Untuk melihat pengaruh iterasi terhadap SNR, dilakukan dengan nilai parameter relaksasi sebesar 1 dan dilakukan iterasi hingga 100 kali. Nilai SNR ditentukan dengan persamaan:

$$
S N R(d B)=10 \log _{10}\left(\frac{\sum_{i, j} x(i, j)^{2}}{\sum_{i, j}(x(i, j)-y(i, j))^{2}}\right)
$$

Dengan $x(i, j)$ adalah nilai untuk piksel ke-i dan ke-j untuk citra asli, dan $y(i, j)$ adalah nilai piksel ke-i dan ke-j untuk citra hasil rekonstruksi.

Untuk menentukan pengaruh nilai parameter relaksasi pada jumlah iterasi tertentu pada nilai SNR, dilakukan variasi nilai parameter relaksasi dari 0,1 hingga 2,5 untuk nilai iterasi 10, 25, 50, 75, dan 100 .

Optimasi citra diperoleh untuk nilai blurring (kekaburan) paling kecil dan "stripping" (semacam garis-garis tebal pada citra) yang paling sedikit.

\section{HASIL DAN PEMBAHASAN}

Pertama dilakukan pengambilan fantom Shepp-Logan, lalu dilakukan proyeksi, lalu dilakukan proyeksi balik. Hasil fantom Shep-Logan dan proyeksi balik ditunjukkan oleh Gambar 1.
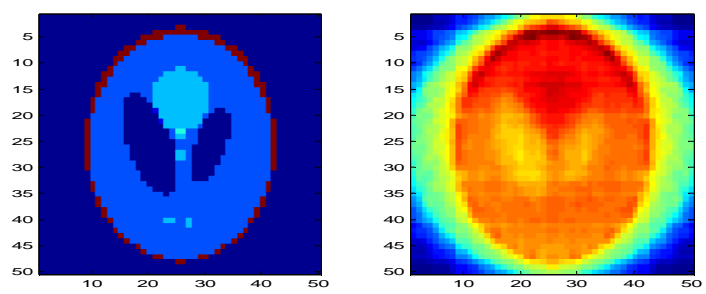

Gambar 1. a adalah citra fantom Shepp-Logan, b. citra hasil proyeksi balik 
Dari Gambar 1. tampak bahwa citra hasil proyeksi balik (b) mengalami banyak kekaburan di sekitar obyek jika dibanding citra asli (a).

Sementara citra hasil rekonstruksi metode SIRT untuk variasi jumlah iterasi pada $\lambda=1$ ditunjukkan oleh Gambar 2 .
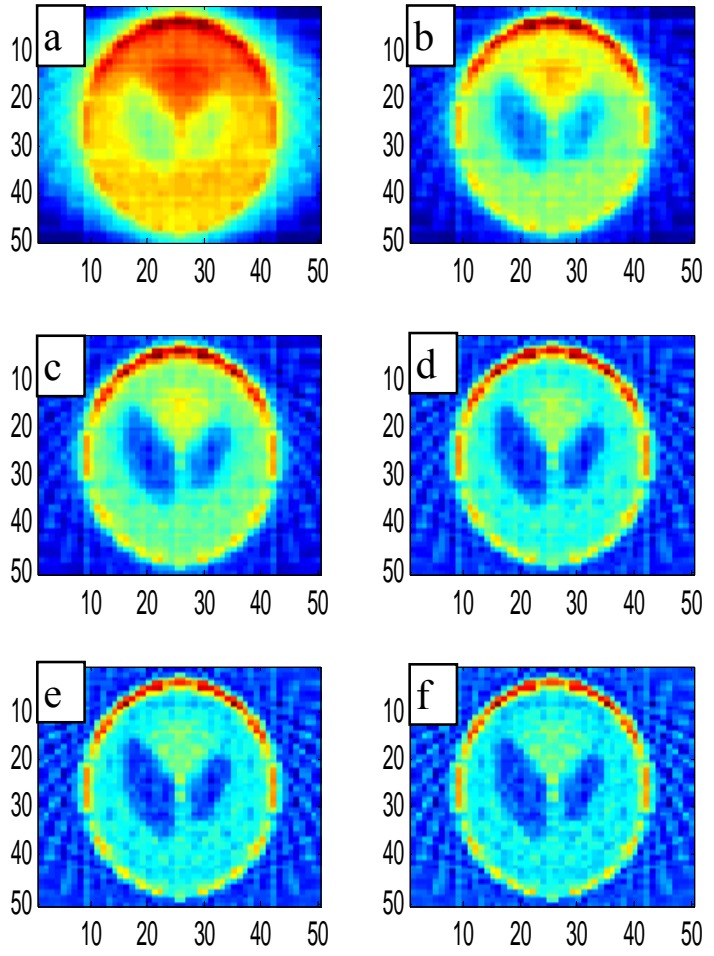

Gambar 2. Citra rekonstruksi pada variasi jumlah iterasi untuk $\lambda=$ 1 , a iterasi 1 , b. iterasi 5 , c. iterasi 10 , d. iterasi 25 , e. iterasi 50 dan f. iterasi 100 .

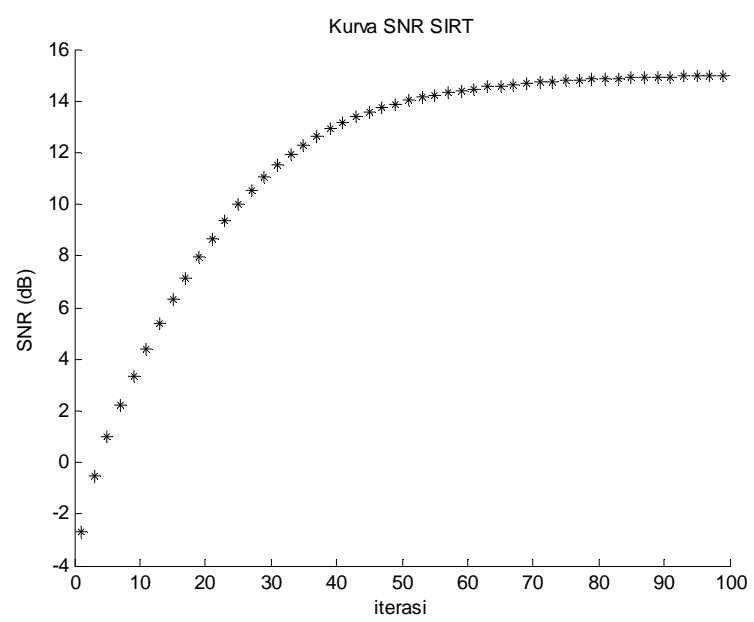

Gambar 3. Grafik SNR untuk tiap iterasi untuk $\lambda=1$..
Dari Gambar 2. tampak bahwa pada iterasi 1 kekaburan masih sangat jelas, dan kekaburan semakin sedikit seiring dengan semakin meningkatnya jumlah iterasi. Menurunnya kekaburan ini juga ditandai dengan naiknya nilai SNR (Gambar 3). Namun menurunnya kekaburan pada iterasi besar diikuti dengan munculnya "stripping", semacam garisgaris tebal pada citra. Tampak bahwa citra rekonstruksi untuk iterasi ke-5 hingga iterasi ke-10, menghasilkan citra dengan kekaburan yang relatif sedikit dan stripping yang juga relatif rendah.

Sementara perhitungan SNR untuk iterasi 1 hingga 100 , dengan nilai $\lambda$ sama dengan 1, ditunjukkan oleh Gambar 3 . Dari Gambar 3. tampak bahwa pada nilai parameter relaksasi 1, semakin banyak iterasi menghasilkan nilai SNR yang semakin tinggi. Namun setelah mencapai iterasi tertentu, nilai SNR mulai mengalami saturasi pada nilai sekitar $15 \mathrm{~dB}$.

Selanjutnya dilakukan rekonstruksi untuk variasi parameter relaksasi $\lambda$ untuk beberapa jumlah iterasi. Citra hasil rekonstruksi metode SIRT variasi $\lambda$ untuk jumlah iterasi 5 ditunjukkan oleh Gambar 4. dan untuk iterasi 10 ditunjukkan oleh Gambar 5.
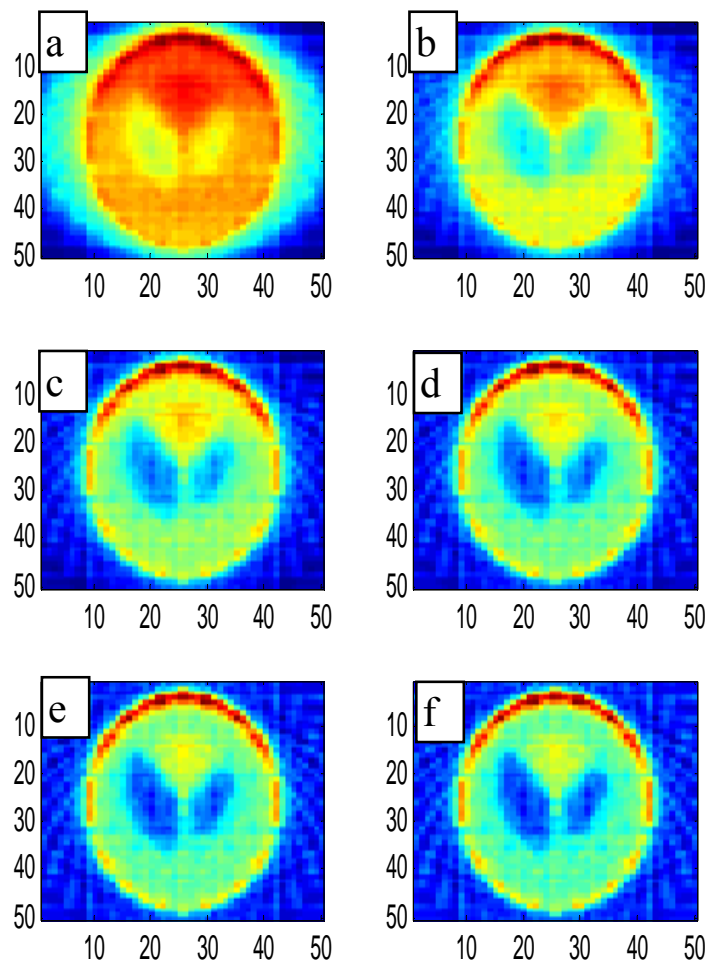

Gambar 4. Citra rekonstruksi pada variasi nilai parameter relaksasi dengan iterasi 5 , a. $\lambda=0,1$, b. $\lambda=0,5$, c. $\lambda=1$, d. $\lambda=$ 1,5 , e. $\lambda=2$ dan f. $\lambda=2,5$. 

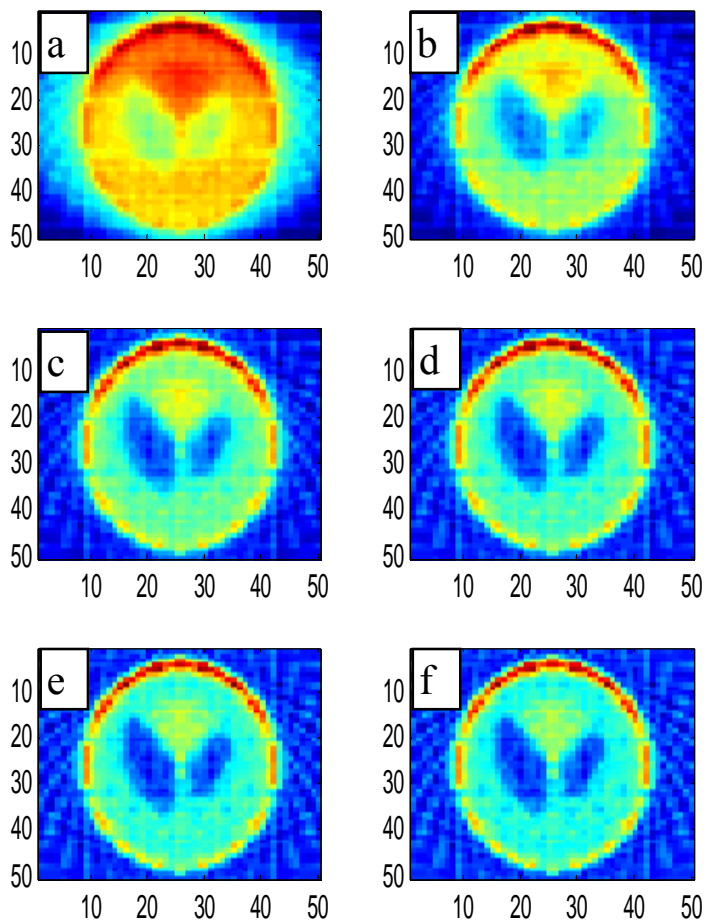

Gambar 5. Citra rekonstruksi pada variasi nilai parameter relaksasi dengan iterasi 10 , a. $\lambda=0,1$, b. $\lambda=0,5$, c. $\lambda=1, \mathrm{~d} . \lambda=$ 1,5 , e. $\lambda=2$ dan f. $\lambda=2,5$.

Dari Gambar 4. dan Gambar 5. tampak bahwa bahwa kenaikan $\lambda$ diikuti oleh penurunan kekaburan, hal ini juga ditandai oleh kenaikan nilai SNR (Gambar 4). Namun kenaikan nilai $\lambda$ juga diikuti oleh munculnya "stripping". Parameter relaksasi ini, memang digunakan untuk melemahkan efek dalam memperbaiki nilai tiap piksel, karena itu dalam aplikasi biasanya dipilih nilai antara 0-1. Nilai diatas 1 memunculkan stripping lagi. Efek ini disebabkan oleh fakta bahwa kesalahan dalam kalkulasi tidak cukup dilemahkan, sehingga akhirnya memunculkan kesalahan pada citra hasil rekonstruksi. Dari Gambar 4 dan Gambar 5 tampak bahwa nilai $\lambda$ antara 0,5 hingga 1 menghasilkan citra rekonstruksi paling baik, yaitu sedikit kekaburan dan sedikit stripping.

Sementara perhitungan SNR untuk variasi $\lambda$ pada iterasi 10, 25,50, 75 dan 100 ditunjukkan oleh Gambar 6. Dari Gambar tampak bahwa semakin semakin besar nilai $\lambda$, menghasilkan menghasilkan nilai SNR yang semakin tinggi. Namun setelah mencapai iterasi tertentu, nilai SNR mulai mengalami saturasi pada nilai sekitar $15 \mathrm{~dB}$. Nilai saturasi juga sangat dipengaruhi oleh jumlah iterasi. Jumlah iterasi semakin besar, nilai saturasi diperoleh untuk $\lambda$ yang semakin kecil.

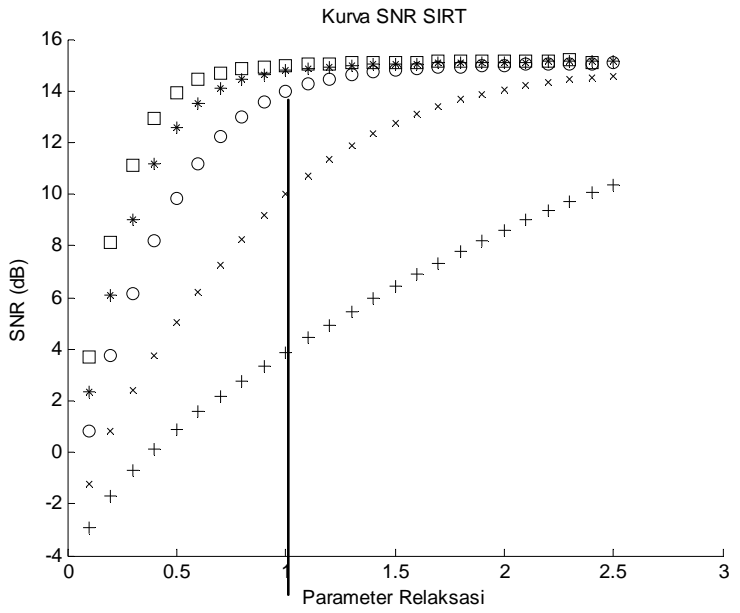

Gambar 5. Grafik SNR untuk variasi parameter relaksasi $\lambda$, untuk iterasi ke-10 (+), 25 (x), 50 (o), $75(*), \quad$ dan $100(\square)$.

\section{KESIMPULAN}

Nilai SNR sangat dipengaruhi oleh jumlah iterasi dan parameter relaksasi. Semakin banyak iterasi dan semakin besar nilai parameter relaksasi menghasilkan nilai SNR yang semakin tinggi, namun setelah mencapai jumlah iterasi dan nilai parameter relaksasi tertentu, nilai SNR mengalami saturasi. Diperoleh citra dengan kekaburan dan stripping paling sedikit pada iterasi antara 5 hingga 10 dan nilai parameter relaksasi antara 0,5 hingga 1 .

\section{PUSTAKA}

[1] H. Guan and R. Gordon, Aprojection acces order for speedy convergence of ART: a multilevel scheme for computed tomography, Phys. Med. Biol., vol. 39, 1994, pp. 2005-2022.

[2] J. T. Bushberg, J. A. Seibert, and J. M. Boone, The Essential Physics of Medical Imaging, Lippicott Williams \& Wilkins, Philadelphia, 2002.

[3] C. E. Widodo, K. Kusminarto, and G. B. Suparta, Tomographic image reconstruction from a sparse projection data using sinogram interpolation, IJET-IJENS, vol. 11, no. 05, 2001, pp. 86-89.

[4] G. N. Sutapa dan C. Anam, Uji kecepatan rekonstruksi citra pada CT-Scan metode Back-Projection (BP) dan metode Filtered Back-Projection (FBP) dengan pemfilteran pada domain spasial, Berkala Fisika, vol. 14, no. 2, 2011, p.33-40.

[5] T. Elfving, P. C. Hansen., T. Nikazab, Semiconvergence and relaxation parameters for projected SIRT algorithm, SIAMJ. SCI. Comput, vol. 34, no. 4, 2012, pp. A2000-A2012.

[6] S. Banglian, P. Lihui., Y. Danya, and Z. Baofen Z., An improved SIRT for electrical capacitance tomography., $1 s t$ World Congress on Industrial Process Tomography, Buxton, Greater Manchester, April 14-17, 1999.

[7] T. Elfving, T. Nikazab. And P. C. Hansen, Semi-convergence and relaxation parameters for a class of SIRT algorithms, Electronic Transactions on Numerical Analysis, vol. 37, 2010, pp. 321-336.

[8] T. V. Hemelryck, The implementation of iterative reconstruction algorithms in MATLAB, Masters Thesis, Department of Industrial Sciences and Technology, University College of Antwerp, Belgium, 2007. 